\title{
CORRECTIONS
}

\section{Restoring invisible and abandoned trials: a call for people to publish the findings}

The $B M J$ would like to apologise for not acknowledging the source for the cover illustration of the 22 June 2013 issue, which also appears in this Analysis article in print and as a black and white illustration online (BMJ 2013;346:f2865, doi:10.1136/ bmj.f2865). Although Paul Boston is the actual cover artist, as credited in print, and Ronan Haughey re-drew the black and white illustration online, Yuko Hara is the original artist whose drawing served as a model for both illustrations with her permission. The original drawing Yuko Hara supplied to us can be found below.

Cite this as: BMJ 2013;346:f4223

๑ BMJ Publishing Group Ltd 2013 


\section{Figure}

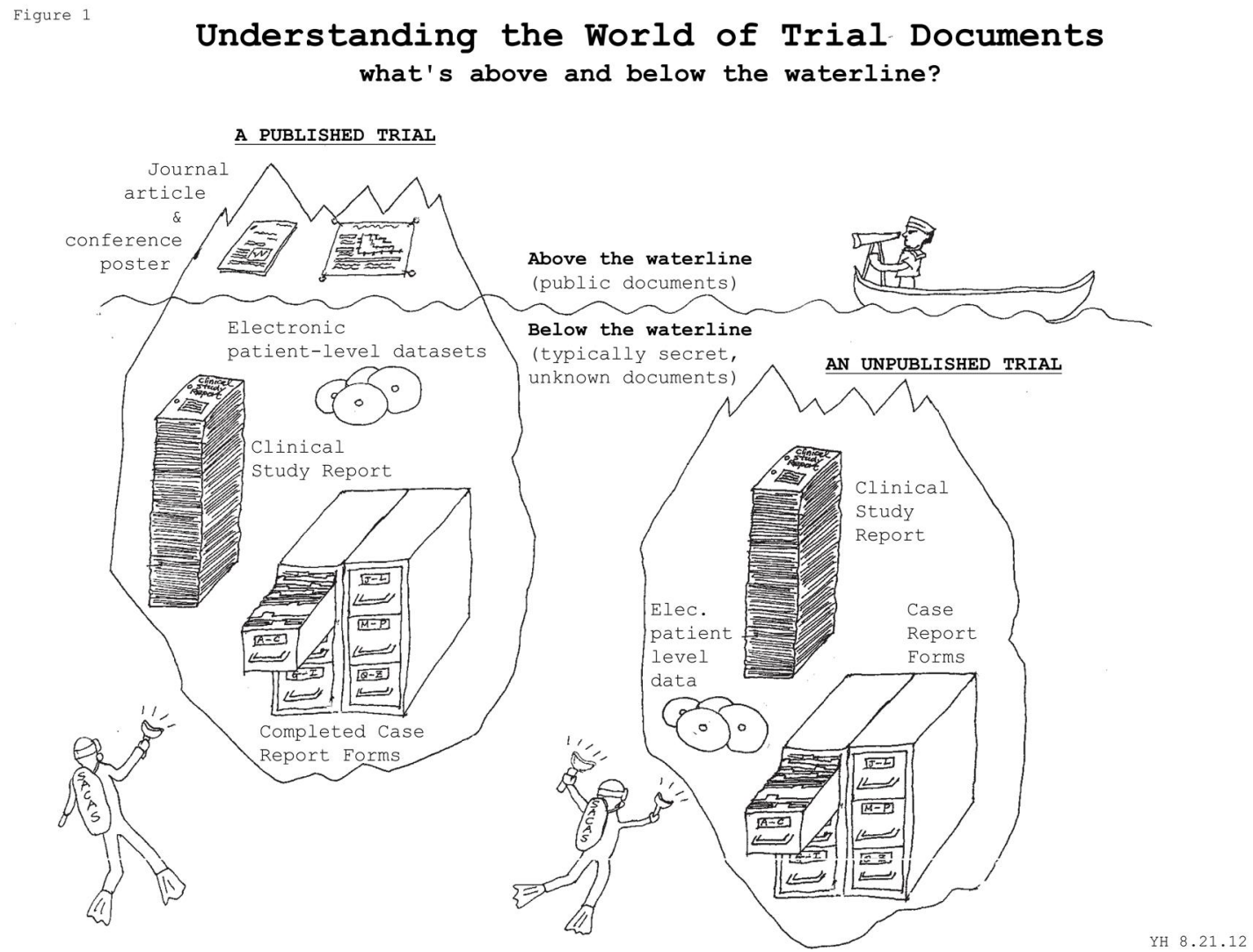

